\title{
Polycarbonate-based thermoplastic polyurethane elastomers modified by DMPA
}

\section{Magdalena Rogulska ${ }^{1}$}

Received: 17 July 2018 / Revised: 19 September 2018 / Accepted: 26 November 2018 / Published online: 29 November 2018

(c) The Author(s) 2018

\begin{abstract}
Thermoplastic polyurethane elastomers (TPUs) containing aliphatic polycarbonate soft segments and hard segments formed by 1,1'-methanediylbis(4-isocyanatocyclohexane) or 1,6-diisocyanatohexane and a combination of two chain extenders, i.e., 2,2'-[sulfanediylbis(benzene-1,4-diyloxy)]diethanol and 3-hydroxy2-(hydroxymethyl)-2-methylpropanoic acid (DMPA), were synthesized in a onestep catalyzed melt polyaddition process. The obtained colorless, transparent and high-molar-mass materials, which differ in the content of the soft segments (30 or $45 \mathrm{~mol} \%$ ) and DMPA (10 or $20 \mathrm{~mol} \%$ ), were subjected to a series of test. Their structure was examined by FTIR spectroscopy, and the thermal properties were studied using differential scanning calorimetry and thermogravimetry. Moreover, their Shore A/D hardness, tensile, adhesive and optical properties were determined. These modified by an ionic chain extender TPUs were characterized by generally enhanced transmittance (up to $92.7 \%$ at $800 \mathrm{~nm}$ ), tensile strength (up to $49.3 \mathrm{MPa}$ ), hardness and adhesive strength, and decreased elongation at break with a slightly worsened thermal stability in comparison with the non-modified ones.
\end{abstract}

Keywords Sulfur-containing polyurethanes - Aliphatic-aromatic chain extender . Aliphatic diisocyanates $\cdot$ Thermal properties $\cdot$ Mechanical and adhesive properties

\section{Introduction}

Thermoplastic polyurethane elastomers (TPUs) are segmented copolymers of alternately distributed flexible soft segments and more rigid hard segments, containing urethane. To synthesize conventional TPUs polyester, polyether and polycarbonate diols are utilized as soft segments, while to construct hard segments one uses aliphatic diols (mainly butane-1,4-diol (BD)) and aromatic (mainly

Magdalena Rogulska

mrogulska@umcs.lublin.pl

1 Department of Polymer Chemistry, Faculty of Chemistry, Maria Curie-Skłodowska University, ul. Gliniana 33, 20-614 Lublin, Poland 
1,1'-methanediylbis(4-isocyanatobenzene) (MDI)) or aliphatic diisocyanates (mainly 1,1'-methanediylbis(4-isocyanatocyclohexane (HMDI)). Although TPUs find wide application in various areas, such as in medicine, footwear and automobile industry, new materials of better properties and multiple use are still needed. Thus, modifications of conventional TPUs both in their main chain, side chain as well as polymer surface itself are carried out [1-14].

Recently, I and my colleagues presented TPUs modified in the main chain [15-18]. They were obtained from non-conventional chain extenders, i.e., 2,2'-[sulfanediylbis(benzene-1,4-diyloxy)]diethanol (diol OSOE), 2,2'-[oxybis(benzene-1,4-diylsulfanediyl)]diethanol or 2,2'-[sulfanediylbis(benzene1,4-diylsulfanediyl)]diethanol, commercial diisocyanates, such as MDI, HMDI and 1,6-diisocyanatohexane (HDI), and commercial polymer diols, such as aliphatic polyether diol of $\bar{M}_{\mathrm{n}}=1000 \mathrm{~g} / \mathrm{mol}$ and aliphatic polycarbonate diol of $M_{\mathrm{n}}=2000 \mathrm{~g} /$ mol (PCD). These polymers revealed relatively good thermal stability and tensile strength (up to 44 MPa). Moreover, TPUs based on aliphatic diisocyanates $[16,18]$ were resistant to becoming yellow and in some cases showed good transparency. Having applied the above-mentioned sulfur-containing chain extenders, we received polymers with both better adhesive properties to metals and improved refractive index and transparency when compared to those created with conventional chain extender $[16,18]$.

The present paper is devoted to a further modification of TPUs which covers the introduction of carboxylic groups into hard segments by using 3-hydroxy2-(hydroxymethyl)-2-methylpropanoic acid (DMPA). For the purpose of the research, I chose some of the previously described TPUs, i.e., based on diol OSOE, HDI or HMDI and PCD [16].

Such functionalized polyurethanes are materials greatly valued in biomedicine as the presence of the carboxylic groups enhances their biocompatibility; on the other hand, owing to the grafting and combining of different polymers, these groups may be used to modify the surface [19-21]. These polymers may also be applied to obtain anionomers after they undergo the process of ionization of the carboxylic groups, and the anionomers may be useful as coatings and adhesives, among others [21-30].

\section{Experimental}

\section{Materials}

The diol OSOE (m.p. $=101-102{ }^{\circ} \mathrm{C}$, after recrystallization first from methanol/water and next from 1,2-dichloroethane) was prepared from 4,4'-sulfanediyldiphenol and ethylene carbonate by a modified procedure described by Penczek et al. [31]. PCD (Desmophen ${ }^{\circledR}$ C2200) of $\bar{M}_{\mathrm{n}}=2000 \mathrm{~g} / \mathrm{mol}$ and HMDI $\left(99.5 \%\right.$, Desmodur $\mathrm{W}^{\circledR}$ ) were kindly supplied from Covestro AG (Germany). Before being used, the PCD was heated at $90{ }^{\circ} \mathrm{C}$ in vacuo for $10 \mathrm{~h}$, while HDI $(99 \%)$ and dibutyltin dilaurate (DBTDL) from Merck-Schuchardt (Germany), DMPA from Sigma-Aldrich (Germany) and HMDI were used as received. 


\section{TPU synthesis}

HDI- and HMDI-based TPUs that were obtained differed in the content of the PCD soft segments, i.e., 30 or $45 \mathrm{~mol} \%$, as well as the content of DMPA, i.e., 10 or $20 \mathrm{~mol} \%$. Therefore, the following system of designation was adopted: $\mathrm{X}-\mathrm{Y}-\mathrm{Z}$, where $\mathrm{X}$ is the abbreviation of diisocyanate, $\mathrm{Y}$ refers to the PCD content and Z represents the DMPA content.

The TPUs were synthesized, according to Fig. 1, by a one-step catalyzed melt polyaddition process from the PCD, DMPA, diol OSOE and HDI or HMDI at the $\mathrm{NCO} / \mathrm{OH}$ molar ratio of 1.05 .

The typical procedure for the synthesis of the TPUs followed the formula: the PCD, DMPA and diol OSOE (0.01 mol together) and diisocyanate (0.0105 mol) were heated with stirring under dry nitrogen to $110{ }^{\circ} \mathrm{C}$ in an oil bath. A catalytic amount of DBTDL (about $3.2 \times 10^{-5} \mathrm{~mol}$ ) was added to the formed clear melt and polymerization rapidly began at vigorous stirring. The reaction temperature was gradually raised to $135{ }^{\circ} \mathrm{C}$, and the formed colorless rubber-like product was additionally heated at this temperature for $2 \mathrm{~h}$.

\section{Measurement methods}

Number $\left(\bar{M}_{\mathrm{n}}\right)$ and mass $\left(\bar{M}_{\mathrm{w}}\right)$ average molar masses and the molar-mass dispersity $\left(Đ M, Ð \mathrm{M}=\bar{M}_{\mathrm{w}} / \bar{M}_{\mathrm{n}}\right.$ ) of the TPUs were determined by gel permeation chromatography (GPC) using a Viscotek GPCMax instrument (USA) equipped with Triple Detector Array TDA305. Tetrahydrofuran (THF) was used as an eluent (flow $=1 \mathrm{~mL} /$ $\min$ ). The operation temperature was set at $35^{\circ} \mathrm{C}$, and a sample concentration of $5 \mathrm{mg} / \mathrm{mL}$ was applied. The molar mass was calibrated with polystyrene standards.

Attenuated total reflectance-Fourier transform infrared (ATR-FTIR) spectra were obtained with a Bruker Tensor 27 FTIR spectrometer (Germany) using thin films. The FTIR spectra were recorded in the spectral range of $600-4000 \mathrm{~cm}^{-1}$ with 32 scans per spectrum with a resolution of $4 \mathrm{~cm}^{-1}$.

Thermogravimetry (TG) was carried out with a Netzsch STA 449 F1 Jupiter thermal analyzer (Germany) in the range of $40-1000{ }^{\circ} \mathrm{C}$ in helium (flow $=20 \mathrm{~mL} / \mathrm{min}$ ) at the heating rate of $10{ }^{\circ} \mathrm{C} / \mathrm{min}$. Sample weights about $10 \mathrm{mg}$ were used.

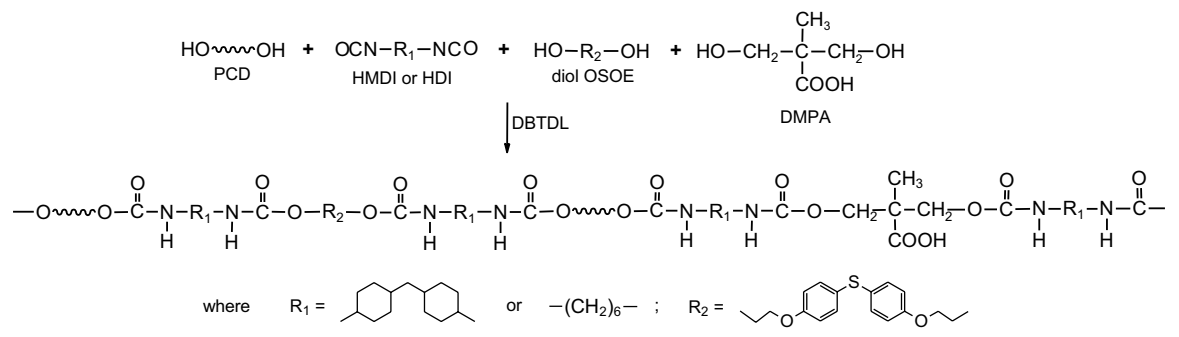

Fig. 1 Synthesis of TPUs 
Scanning calorimetry (DSC) curves were obtained with a Netzsch 204 calorimeter (Germany) in the range of -100 to $200{ }^{\circ} \mathrm{C}$. The reported transitions were taken from first to second heating scans. The scans were performed at the heating/cooling rate of $10{ }^{\circ} \mathrm{C} / \mathrm{min}$ under nitrogen atmosphere (flow $=30 \mathrm{~mL} / \mathrm{min}$ ). Sample weights of about $10 \mathrm{mg}$ were used. Glass transition temperatures $\left(T_{\mathrm{g}} \mathrm{s}\right)$ for the polymer samples were taken as the inflection point on the curves of the heat capacity changes. Melting temperatures $\left(T_{\mathrm{m}} \mathrm{s}\right)$ were read at endothermic peak maxima.

The Shore hardness tests were carried out with a Zwick 7206/H04 durometer (Germany), type A and D. The measurements were taken after $15 \mathrm{~s}$ at the temperature of $23^{\circ} \mathrm{C}$.

Tensile testing was performed on a Zwick/Roell Z010 (Germany) tensile testing machine according to Polish Standard PN-81/C-89034 (EN ISO Standard 527$1: 1996$ and $527-2: 1996)$ at the speed of $100 \mathrm{~mm} / \mathrm{min}$ at $23{ }^{\circ} \mathrm{C}$; tensile test pieces $1 \mathrm{~mm}$ thick and $6 \mathrm{~mm}$ wide (for the section measured) were cut from the pressed sheet.

Press molding was done with a Carver hydraulic press (USA) at $105-155{ }^{\circ} \mathrm{C}$ under 10-30 MPa pressure.

The single-lap shear strength of the polymers to copper plate, $100 \mathrm{~mm} \times 25 \mathrm{~mm} \times 1.5 \mathrm{~mm}$, was measured in accordance with Polish Standard PN-EN 1465:2009 by using a Zwick/Roell Z010 (Germany). The adhesive joint, $12.5 \mathrm{~mm} \times 25 \mathrm{~mm} \times 0.2 \mathrm{~mm}$, was prepared by pressing the polymer between the ends of two copper plates at $105-155^{\circ} \mathrm{C}$ (prepared according to PN-EN-13887:2005) and then leaving them under a pressure of $30 \mathrm{MPa}$ to cool to room temperature. Next, the plates were fixed by tensile testing machine clips and underwent tensile testing, at the speed of $2 \mathrm{~mm} / \mathrm{min}$ at $23{ }^{\circ} \mathrm{C}$.

The ultraviolet-visible (UV-VIS) spectra of the compression-molded 1-mmthick sheets of the polymers were collected with a UV-1800 (Shimadzu, Japan) UV spectrophotometer in the range of 300-900 nm, with a sampling interval of $0.5 \mathrm{~nm}$.

Refractive index measurements were taken at $23^{\circ} \mathrm{C}$ by a Conbest Abbe's Refractometer Type 325 instrument (Poland) in keeping with method A of European Standard EN ISO 489:1999. 1-Bromonaphthalene was used between the sample film and the prism shield. The polymers were in the form of the compression-molded 1-mm-thick sheets.

\section{Results and discussion}

The TPUs obtained were colorless, transparent materials. The HDI-based TPUs were insoluble in numerous organic solvents, such as THF, $N, N$-dimethylacetamide (DMAc), $N, N$-dimethylformamide (DMF), $N$-methyl-2-pyrrolidone (NMP), 1,1,2,2-tetrachloroethane (TChE) and dimethyl sulfoxide (DMSO); hence, their molar masses were not to be determined. On the other hand, the HMDI-based ones showed much lower resistance to the mentioned solvents, which can be caused by their amorphous structures (see DSC results). They were completely soluble in THF, DMAc, DMF and TChE, partially soluble in NMP and insoluble in DMSO. As given in Table 1 , these polymers exhibited high values of $\bar{M}_{\mathrm{n}}$ (in the range of 
Table 1 Designations and GPC data of the TPUs

\begin{tabular}{|c|c|c|c|c|c|c|c|}
\hline \multirow[t]{2}{*}{ TPU } & \multirow[t]{2}{*}{ Diisocyanate } & \multirow{2}{*}{$\begin{array}{l}\text { PCD } \\
\text { content } \\
(\mathrm{mol} \%)\end{array}$} & \multirow{2}{*}{$\begin{array}{l}\text { DMPA con- } \\
\text { tent }(\mathrm{mol} \%)\end{array}$} & \multirow{2}{*}{$\begin{array}{l}\text { Hard-segment } \\
\text { content (mas\%) }\end{array}$} & \multicolumn{3}{|l|}{ GPC } \\
\hline & & & & & $\bar{M}_{\mathrm{n}}(\mathrm{g} / \mathrm{mol})$ & $\bar{M}_{\mathrm{w}}(\mathrm{g} / \mathrm{mol})$ & ĐM \\
\hline H-30-10 & HDI & 30 & 10 & 37.8 & $-^{\mathrm{a}}$ & $-{ }^{\mathrm{a}}$ & $-{ }^{\mathrm{a}}$ \\
\hline H-30-20 & & 30 & 20 & 36.7 & $-{ }^{\mathrm{a}}$ & $-{ }^{\mathrm{a}}$ & $-^{\mathrm{a}}$ \\
\hline H-45-10 & & 45 & 10 & 26.2 & $-{ }^{\mathrm{a}}$ & $-{ }^{\mathrm{a}}$ & $-{ }^{\mathrm{a}}$ \\
\hline H-45-20 & & 45 & 20 & 25.1 & $-^{\mathrm{a}}$ & $-^{\mathrm{a}}$ & $-^{\mathrm{a}}$ \\
\hline HM-30-10 & HMDI & 30 & 10 & 44.1 & $143 \times 10^{3}$ & $230 \times 10^{3}$ & 1.61 \\
\hline HМ-30-20 & & 30 & 20 & 43.2 & $123 \times 10^{3}$ & $255 \times 10^{3}$ & 2.07 \\
\hline HM-45-10 & & 45 & 10 & 32.2 & $110 \times 10^{3}$ & $249 \times 10^{3}$ & 2.26 \\
\hline HМ-45-20 & & 45 & 20 & 31.3 & $125 \times 10^{3}$ & $219 \times 10^{3}$ & 1.75 \\
\hline
\end{tabular}

${ }^{\mathrm{a}} \mathrm{TPU}$ insoluble in THF and other solvents

$110 \times 10^{3}-143 \times 10^{3} \mathrm{~g} / \mathrm{mol}$ ) and $\bar{M}_{\mathrm{w}}$ (in the range of $219 \times 10^{3}-255 \times 10^{3} \mathrm{~g} / \mathrm{mol}$ ), as well as a relatively low molar-mass dispersity, ranging from 1.61 to 2.26 , as for polyurethanes synthesized by melt polymerization method. Polyurethanes with similar molar-mass dispersity were also obtained by other researchers [32-34].

Chemical structures of all the TPUs were examined by ATR-FTIR spectroscopy. The received spectra were consistent with their proposed structures. There were observed absorptions peaks characteristics of the urethane, carbonate, carboxylic and ether groups, benzene ring, as well as methylene and methyl groups. No isocyanate peak about $2270 \mathrm{~cm}^{-1}$ was seen in any spectra, indicating full NCO conversion. The main absorption bands are given below, whereas representative spectra are visible in Fig. 2.

$\left(\mathrm{cm}^{-1}\right)$ : 1534-1522 (N-H bending) and 3366-3324 (N-H stretching) of the urethane group; $1740-1685(\mathrm{C}=\mathrm{O}$ stretching of the urethane, carbonate and carboxylic groups); 1244-1242 (C-O stretching of the carbonate and carboxylic groups and asymmetric C-O-C stretching in aliphatic-aromatic ether); 1056-1045 (symmetric $\mathrm{C}-\mathrm{O}-\mathrm{C}$ stretching in aliphatic-aromatic ether); 792-791 (out-of-plane bending of O-CO-O); 2937-2925 and 2862-2856 (asymmetric and symmetric C-H stretching) and 1459-1457 (asymmetric $\mathrm{C}-\mathrm{H}$ bending of $\mathrm{CH}_{3}$ and $\mathrm{CH}_{2}$ ); 1379-1377 (symmetric $\mathrm{C}-\mathrm{H}$ bending of $\mathrm{CH}_{3}$ ); 1593 and 1492-1491 (C-C stretching of benzene ring); 831-822 ( $\mathrm{C}-\mathrm{H}$ bending of $p$-disubstituted benzene ring).

Thermal properties of the synthesized TPUs were determined by using TG and DSC analyses.

The TPUs exhibited good thermal stability as indicated by the temperatures of $1 \%\left(T_{1}\right), 5 \%\left(T_{5}\right), 10 \%\left(T_{10}\right)$ and $50 \%\left(T_{50}\right)$ mass loss designed from the TG curves and are given in Table 2. However, these temperature mass loss indicators were generally somewhat lower than those obtained for the analogous non-modified TPUs [16]. Then, the introduction of DMPA into the structure of the polymer slightly degrades its thermal stability, the more so the higher is its content. Interdependence of this kind was present in similar TPUs based on diphenylmethane-derivative chain extenders $[35,36]$. 


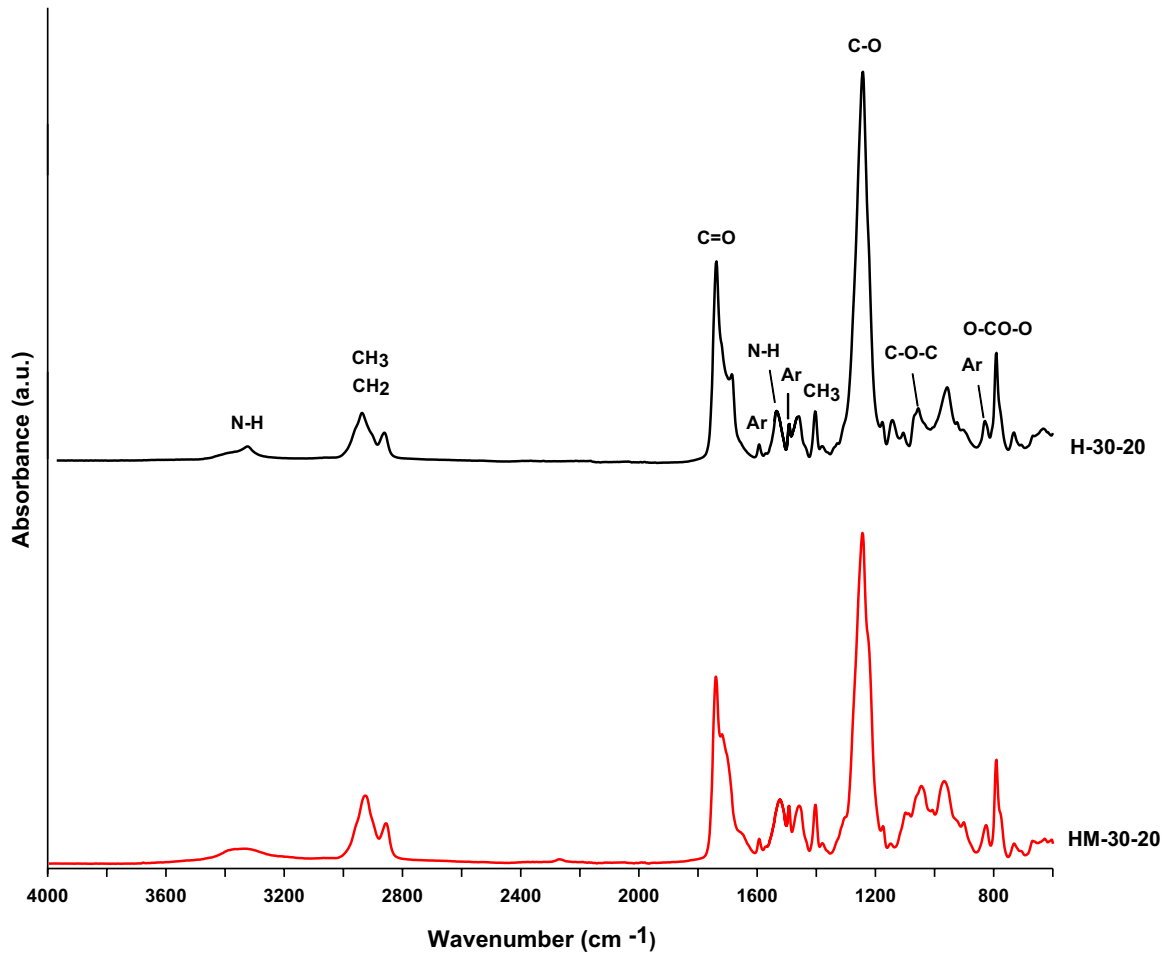

Fig. 2 ATR-FTIR spectra of selected TPUs

Table 2 TG data of the TPUs

\begin{tabular}{llllll}
\hline TPU & $T_{1}^{\mathrm{a}}\left({ }^{\circ} \mathrm{C}\right)$ & $T_{5}^{\mathrm{b}}\left({ }^{\circ} \mathrm{C}\right)$ & $T_{10}^{\mathrm{c}}\left({ }^{\circ} \mathrm{C}\right)$ & $T_{50}^{\mathrm{d}}\left({ }^{\circ} \mathrm{C}\right)$ & $T_{\max }^{\mathrm{e}}\left({ }^{\circ} \mathrm{C}\right)$ \\
\hline H-30-10 & 264 & 290 & 302 & 344 & $292,340,344,402$ \\
H-30-20 & 260 & 289 & 300 & 341 & $291,335,344,402$ \\
H-45-10 & 268 & 290 & 304 & 344 & $293,326,342,352,395$ \\
H-45-20 & 264 & 290 & 301 & 341 & $294,331,341,350,397$ \\
HM-30-10 & 263 & 290 & 301 & 341 & $292,336,357,397$ \\
HM-30-20 & 260 & 291 & 301 & 342 & $300,334,345,392$ \\
HM-45-10 & 263 & 290 & 303 & 343 & $290,336,346,399$ \\
HM-45-20 & 261 & 289 & 300 & 341 & $299,335,347,405$ \\
\hline
\end{tabular}

a,b,c,d The temperature of $1 \%, 5 \%, 10 \%$ and $50 \%$ mass loss from the TG curve, respectively

${ }^{\mathrm{e}} \mathrm{The}$ temperature of the maximum rate of mass loss from the differential TG (DTG) curve

The decomposition of all the TPUs was a multistage process. On all DTG curves, two overlapping peaks of high intensity were revealed with their maxima in the range of $334-357^{\circ} \mathrm{C}$ and in the case of polymers H-45-10 and H-45-20 also a slightly perceptible one (at 326 or $331{ }^{\circ} \mathrm{C}$ ); they are all associated with the decomposition mainly urethane and carbonate linkages. In the range of lower temperatures, 
at $290-300{ }^{\circ} \mathrm{C}$, one may notice a peak of much lower intensity, visible as a shoulder. Its intensity was higher for TPUs with a greater DMPA content, and it was not observed for the analogous non-modified ones [16]; thus, it could be ascribed to the first stage of the DMPA unit decomposition. To continue, the peak with the maximum at $392-405{ }^{\circ} \mathrm{C}$ is coupled with the decomposition of aromatic segment containing sulfide and ether groups [16]. Figures 3 and 4 present the DTG and TG curves received for TPUs with $45 \mathrm{~mol} \%$ content of soft segment.

As the previous paper explains [16], the urethane linkage present in the hard segments of the non-modified TPUs decomposed as a result of its dissociation to diisocyanate (HDI or HMDI) and diol OSOE; at the same time, the main decomposition products of the polycarbonate soft segments were carbon dioxide, carbon monoxide, alkenes, aliphatic alcohols and ethers, as shown in Fig. 5. In the described modified
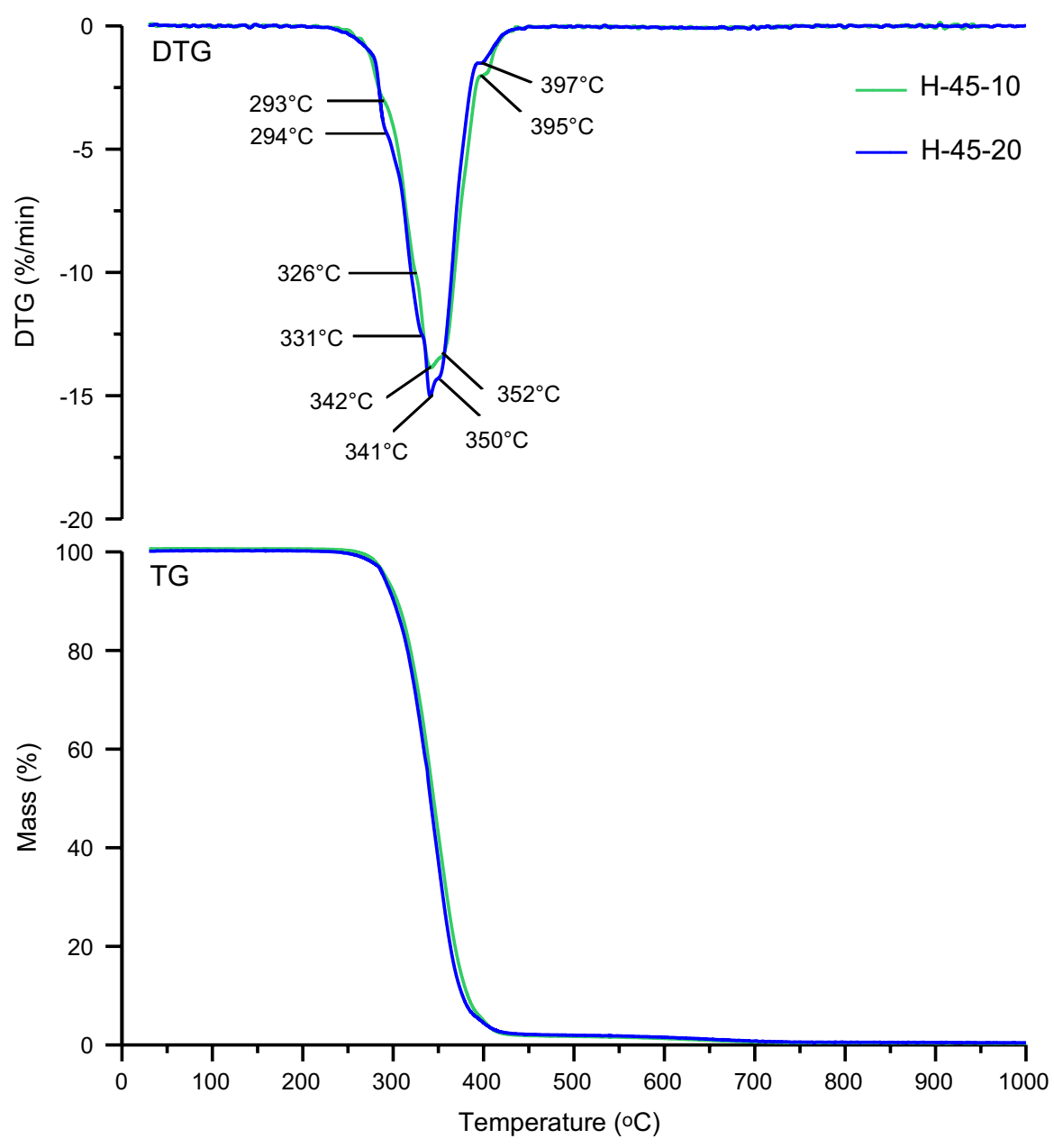

Fig. 3 TG and DTG curves of selected TPUs based on HDI 


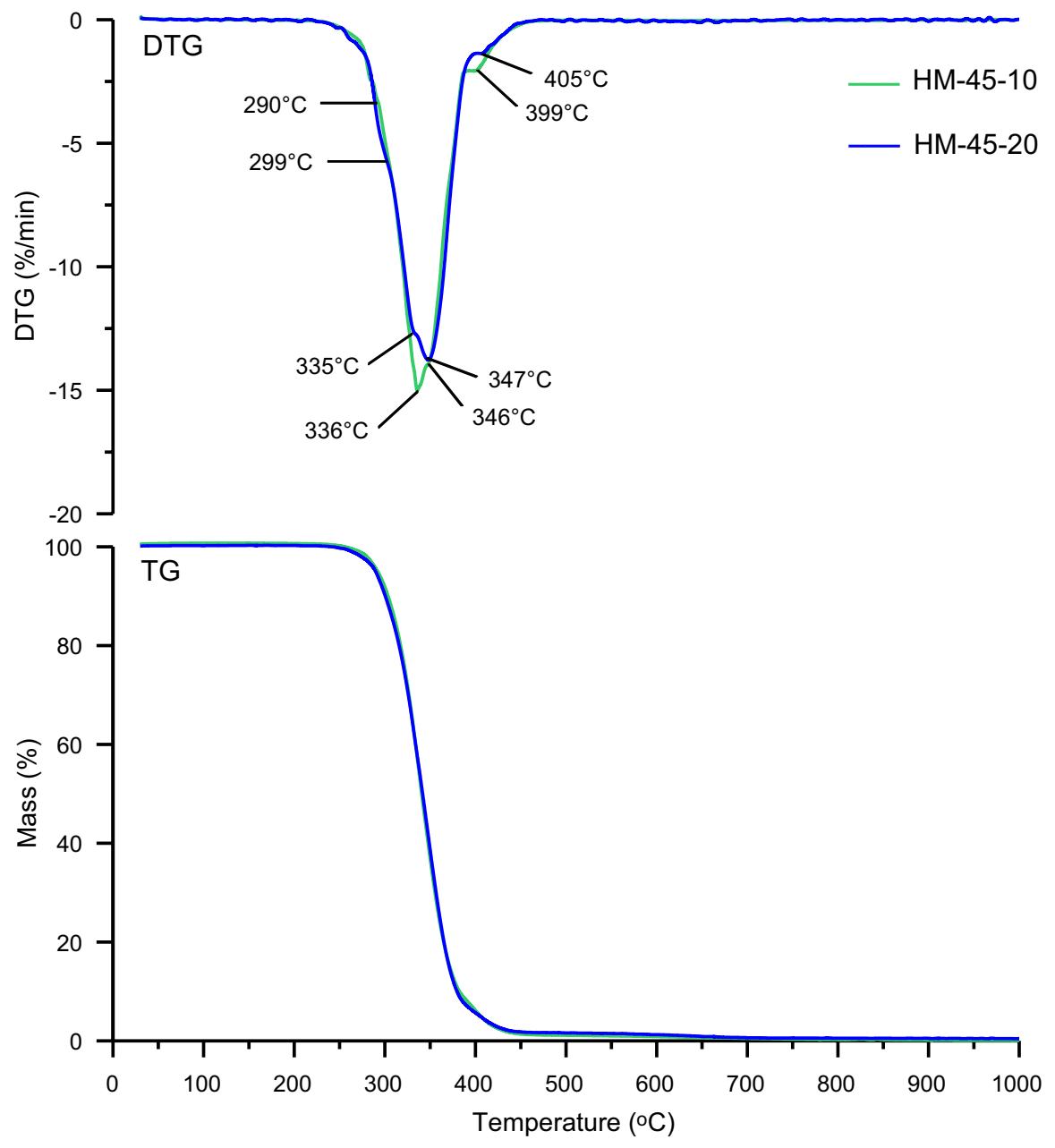

Fig. 4 TG and DTG curves of selected TPUs based on HMDI

TPUs, hard segments formed by DMPA additionally appear. In the case of these segments, it may be assumed that the first is decarboxylation of the DMPa unit and then decomposes urethane linkage with the formation of diisocyanate and 2-methylpropane-1,3-diol, according to Fig. 5. In both cases, diisocyanates may react to form carbodiimides and carbon dioxide. The products of the decomposition of 2-methylpropane-1,3-diol can be alcohols, ethers, aldehydes and water.

The DSC curves of all the HDI-based TPUs (Fig. 6) from the first heating scans showed one or two endothermic peaks with maxima in the range of $63-144{ }^{\circ} \mathrm{C}$, which correspond to the melting of hard-segment domains. The high-temperature peak at $144{ }^{\circ} \mathrm{C}$ observed only for polymer $\mathrm{H}-30-10$ should be assigned to the melting of well-separated domains of the hard segments with a high degree of ordering formed mainly by diol OSOE [16]. With the increase in DMPA content 

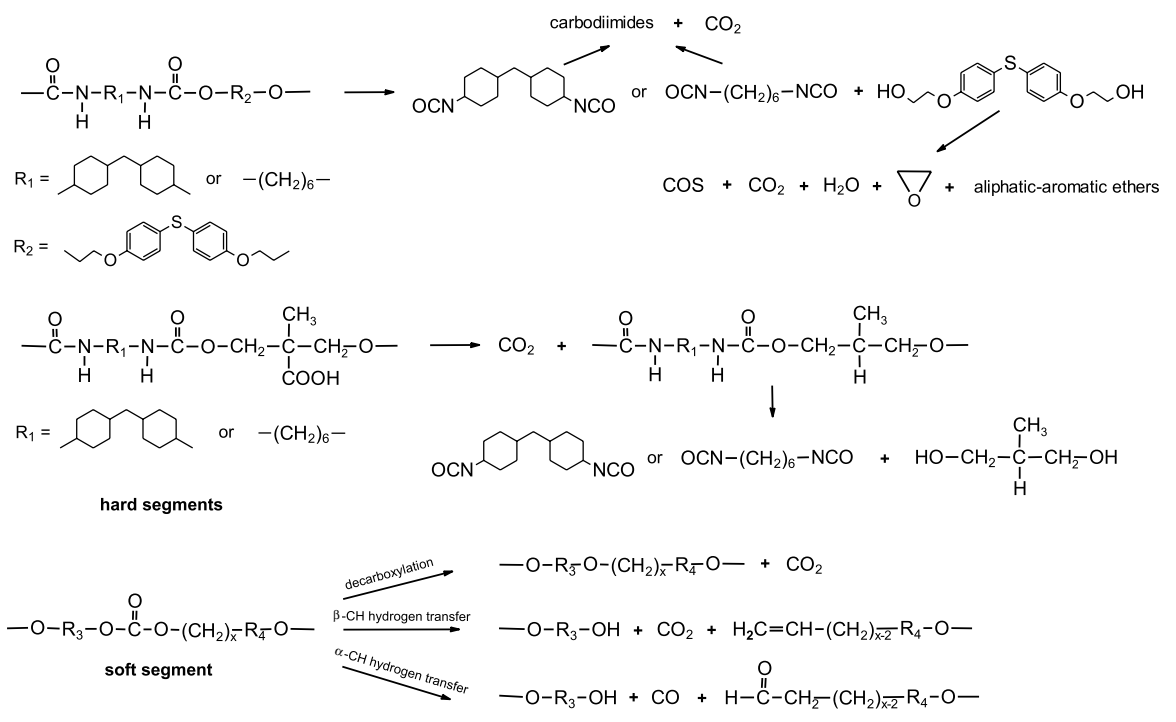

Fig. 5 Mechanism of the thermal decomposition of TPUs

from 10 to $20 \mathrm{~mol} \%$, the possibility of the formation of carboxylic group dimmers grows, which disturbs the ordering of hard-segment domains, so hence significantly lower temperatures of their melting $\left(63-80{ }^{\circ} \mathrm{C}\right)$ and smaller heat $(\Delta H)$ of this transition. In the case of TPUs containing $45 \mathrm{~mol} \%$ PCD soft segments, whose non-modified analog H-45 was characterized by a low degree of ordering, the introduction of DMPA had a limited effect on their tendency to form ordered structures. The DSC curves received for these polymers displayed only the lowtemperature endothermic peaks with maxima in the range of $63-85^{\circ} \mathrm{C}$. However, when comparing $\Delta H$ values one may conclude that these modified TPUs revealed a lower degree of ordering than the non-modified ones [16], the lower the more DMPA was used. The absence of endothermic peaks in the second heating scans points to a limited tendency of these polymers to form ordered structures.

These TPUs exhibited similar $T_{\mathrm{g}} \mathrm{s}$ of the soft segment in the range of -36 to $-29{ }^{\circ} \mathrm{C}$ (see Table 3). Somewhat lower values were observed for the polymers containing $45 \mathrm{~mol} \% \mathrm{PCD}$, both in the first and second heating scans. The readings indicate weaker influence of the composition of these polymers on the degree of microphase separation, considered as relatively good. There is little difference between $T_{\mathrm{g}}$ values of pure PCD soft segment $\left(-42^{\circ} \mathrm{C}\right)$ and the TPU.

The DSC curves of all the HMDI-based TPUs (Fig. 6) from both heating scans displayed only glass transition. In the case of these amorphous polymers, one observes bigger $T_{\mathrm{g}} \mathrm{s}$ differentiation (see Table 3 ). Significantly lower values $\left(-22-(-12){ }^{\circ} \mathrm{C}\right.$ vs. $\left.-9-2{ }^{\circ} \mathrm{C}\right)$ and therefore a higher degree of microphase separation were present in polymers with the higher content of the soft segments. On the other hand, considering $T_{\mathrm{g}} \mathrm{s}$ only from the second heating scans, the influence of the DMPA amount is revealed, and so more DMPA means lower $T_{\mathrm{g}}$. 


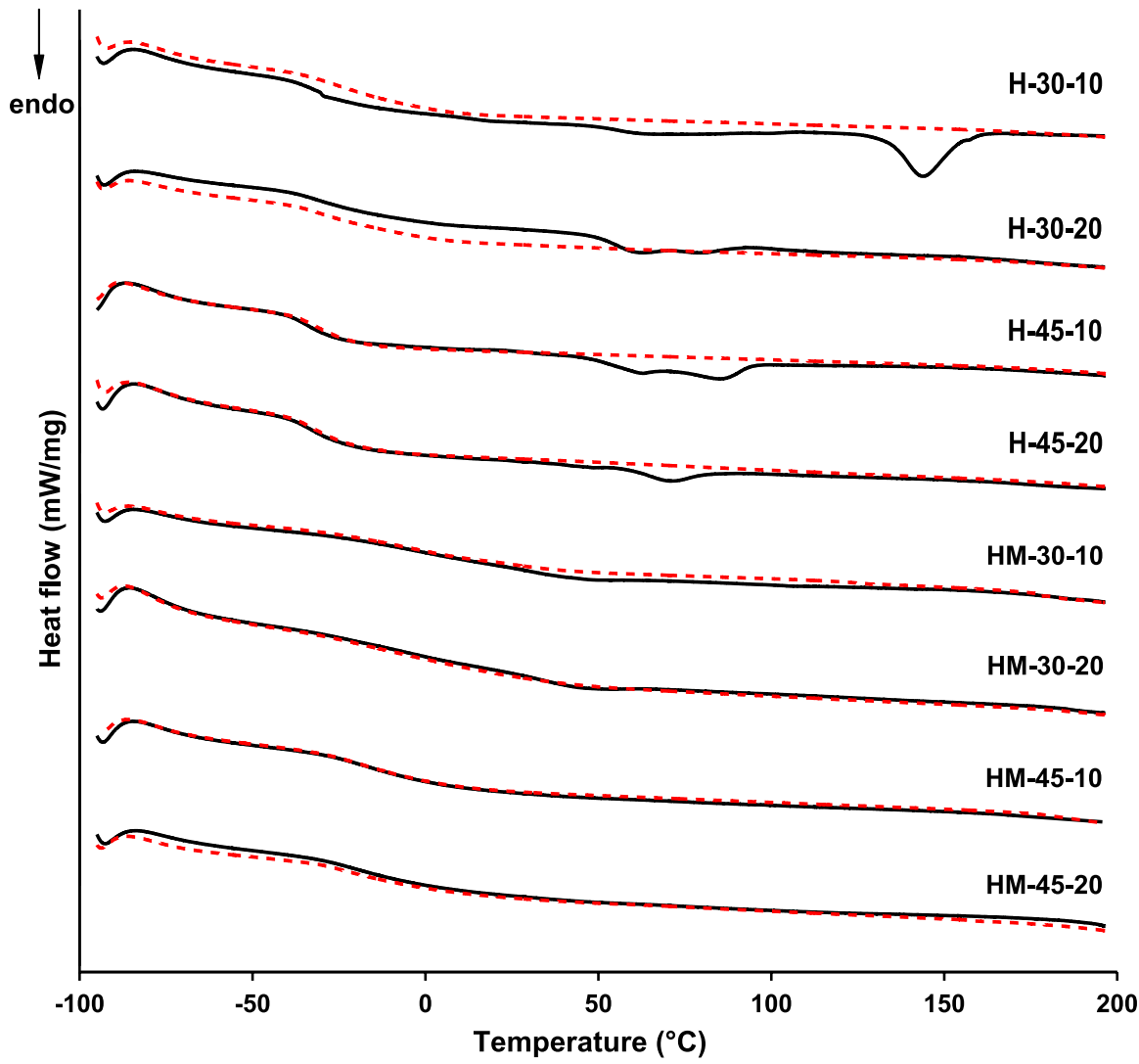

_ first heating scan _ - - second heating scan

Fig. 6 DSC curves of TPUs

Table 3 DSC data of the TPUs

\begin{tabular}{|c|c|c|c|c|c|c|}
\hline \multirow[t]{2}{*}{ TPU } & \multicolumn{2}{|c|}{$T_{\mathrm{g}}\left({ }^{\circ} \mathrm{C}\right)$} & \multicolumn{2}{|l|}{$T_{\mathrm{m}}\left({ }^{\circ} \mathrm{C}\right)$} & \multicolumn{2}{|l|}{$\Delta H(\mathrm{~J} / \mathrm{g})$} \\
\hline & $\mathrm{I}^{\mathrm{a}}$ & $\mathrm{II}^{\mathrm{a}}$ & $\mathrm{I}^{\mathrm{a}}$ & $\mathrm{II}^{\mathrm{a}}$ & $\mathrm{I}^{\mathrm{a}}$ & $\mathrm{II}^{\mathrm{a}}$ \\
\hline H-30-10 & -30 & -30 & 65,144 & & $4.8 ; 13.8$ & \\
\hline H-30-20 & -32 & -29 & 63,80 & & 7.8 & \\
\hline H-45-10 & -36 & -33 & 63,85 & & 10.6 & \\
\hline H-45-20 & -35 & -33 & 72 & & 5.0 & \\
\hline HM-30-10 & 0 & 2 & & & & \\
\hline HM-30-20 & 0 & -9 & & & & \\
\hline HM-45-10 & -20 & -12 & & & & \\
\hline HМ-45-20 & -19 & -22 & & & & \\
\hline
\end{tabular}

${ }^{\mathrm{a}}$ I and II, first and second heating scans, respectively 
As resulting from the data in Table 4, using DMPA as a chain extender together with diol OSOE generally causes enhanced transmittance, both at 500 and $800 \mathrm{~nm}$. Particularly, big increase took place for samples H-30-10 and H-3020, whose non-modified analog (H-30) showed much higher degree of ordering [16]. That is the effect of the disturbance of polymer chain regularity and the resulting limitation of the possibility of forming ordered structures. As expected, among the TPUs modified by DMPA higher values of this parameter were exhibited by polymers from HMDI, showing the amorphous structure (see DSC data). It was also found that a better transparency was revealed by polymers with a higher DMPA content, which means a higher amount of carboxylic groups. The higher amount of the carboxylic groups in polymers could cause the formation of higher amount of hydrogen bonds in their structure (physical cross-linking). The UV visible spectra of all TPUs are shown in Fig. 7.

Improved transparency resulting from the increase in DMPA content was also observed for polymers prepared from poly(oxytetramethylene)diol of $M_{\mathrm{n}}=2000 \mathrm{~g} / \mathrm{mol}, \mathrm{HMDI}$ and diphenylmethane-derivative diols [36].

Considering refractive index values given in Table 4, one may say that a clear effect of the DMPA content made itself visible in polymers with higher hard-segment content, in which more of sulfur atoms were replaced by carboxylic groups present in DMPA. As shown in earlier works [15, 16, 35-38], the refractive index largely depends on the content of sulfur atoms in the polymer; if it is higher, the effect is higher value of the refractive index. This is to be ascribed to the fact that polarizability of the sulfur produces a strong interaction between polymers and incident light, and that results in high refractive index, while increasing

Table 4 Optical and adhesive properties of the TPUs

\begin{tabular}{lllrc}
\hline TPU & Refractive index & \multicolumn{2}{l}{$\begin{array}{l}\text { Transmittance } \\
(\%)\end{array}$} & $\begin{array}{l}\text { Lap shear } \\
\text { strength } \\
\text { (MPa) }\end{array}$ \\
\cline { 3 - 4 } & & $T_{500}^{\mathrm{b}}$ & $T_{800}^{\mathrm{b}}$ & \\
\hline $\mathrm{H}^{2}-30^{\mathrm{a}}$ & & 4.6 & 7.3 & 4.4 \\
H-30-10 & 1.516 & 58.7 & 72.6 & 7.0 \\
H-30-20 & 1.513 & 62.3 & 75.4 & 12.3 \\
H-45 & 1.503 & 57.3 & 69.5 & 2.2 \\
H-45-10 & 1.493 & 56.9 & 69.4 & 3.1 \\
H-45-20 & 1.495 & 64.0 & 69.8 & 2.4 \\
HM-30 & 1.521 & 73.1 & 79.0 & 5.8 \\
HM-30-10 & 1.520 & 77.6 & 87.4 & 13.8 \\
HM-30-20 & 1.508 & 83.8 & 90.8 & 16.7 \\
HM-45 & 1.494 & 69.0 & 73.8 & 3.5 \\
HM-45-10 & 1.495 & 79.0 & 86.5 & 5.5 \\
HM-45-20 & 1.495 & 87.3 & 92.7 & 5.9 \\
\hline
\end{tabular}

${ }^{\mathrm{a}}$ TPUs non-modified by DMPA

${ }^{\mathrm{b}}$ Transmittance data at 500 and $800 \mathrm{~nm}$ 


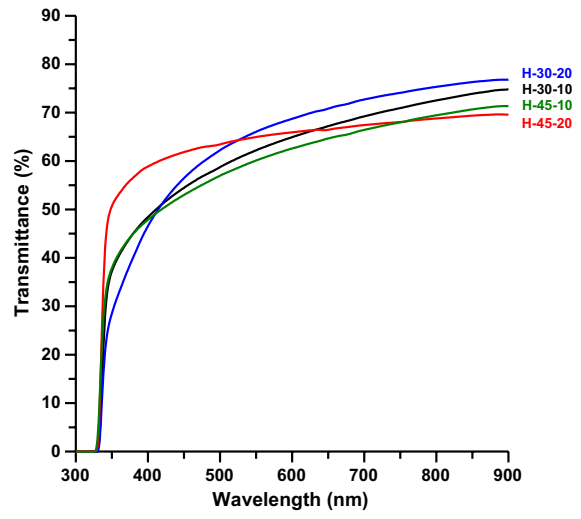

(a)

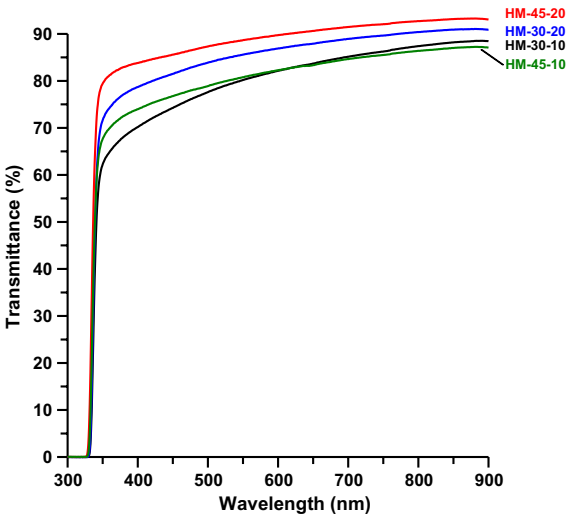

(b)

Fig. 7 UV-Vis spectra of TPUs based on HDI (a) and HMDI (b)

the polarizability of substitute group (e.g., sulfur) can bring about the increase in refractive index of the TPUs synthesized.

Analyzing the data in Table 5 shows that synthesized TPUs were characterized by varied hardness. In both series, higher hardness was exhibited by those with lower PCD soft segment content, i.e., $30 \mathrm{~mol} \%$. To continue, taking into account DMPA content it was concluded that in HDI series less hard were polymers with the lower DMPA content, showing less ordered structures. In contrast, among the amorphous HMDI-series polymers a higher hardness was observed for those containing more DMPA, which were more physically cross-linked. Generally, the same dependences were perceived in the case of the modulus of elasticity values. TPUs based on HMDI showed higher tensile strength than the analogous ones based on HDI: 41.2-49.3 MPa versus 37.8-44.9 MPa and lower elongation at break: 260-350\% versus $430-575 \%$. Figure 8 displays the stress-strain curves for all the TPUs.

Table 5 Mechanical properties of the TPUs

\begin{tabular}{llllll}
\hline TPU & $\begin{array}{l}\text { Hard- } \\
\text { ness } \\
\left({ }^{\circ} \text { Sh }\right)\end{array}$ & $\begin{array}{l}\text { Modulus of } \\
\text { elasticity } \\
(\mathrm{MPa})\end{array}$ & $\begin{array}{l}\text { Tensile } \\
\text { strength } \\
(\mathrm{MPa})\end{array}$ & $\begin{array}{l}\text { Elongation } \\
\text { at break (\%) }\end{array}$ \\
\cline { 2 - 4 } & $\mathrm{A}$ & $\mathrm{D}$ & & & \\
\hline H-30-10 & 88 & 36 & 35.0 & 44.9 & 450 \\
H-30-20 & 87 & 34 & 43.6 & 37.8 & 575 \\
H-45-10 & 86 & 30 & 25.3 & 41.0 & 430 \\
H-45-20 & 81 & 28 & 22.7 & 39.9 & 490 \\
HM-30-10 & 86 & 38 & 45.1 & 48.9 & 260 \\
HM-30-20 & 89 & 40 & 55.1 & 49.3 & 275 \\
HM-45-10 & 69 & 25 & 3.29 & 41.2 & 325 \\
HM-45-20 & 72 & 27 & 4.16 & 44.7 & 350 \\
\hline
\end{tabular}




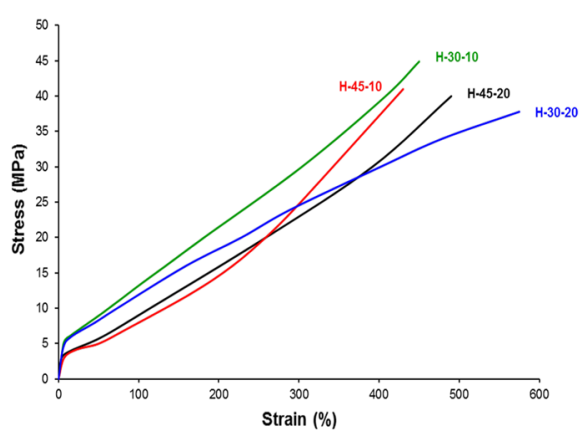

(a)

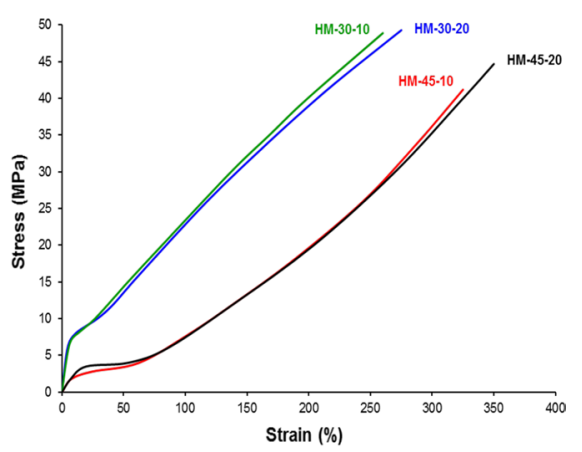

(b)

Fig. 8 Stress-strain curves of TPUs based on HDI (a) and HMDI (b)

In most cases, the modified TPUs were harder than the non-modified ones. The former revealed also much higher tensile strength and lower elongation at break [16].

The introduction of DMPA was beneficial for the values of the lap shear strengths to copper (adhesion) of the TPUs (see Table 1). The newly synthesized TPUs revealed even over three times higher adhesive strength than their nonmodified analogs. On the whole, adhesive strength grew in parallel with growing DMPA amount (more polar carboxylic groups) in the polymer, and that increase was more pronounced in the case of the polymers containing $30 \mathrm{~mol} \% \mathrm{PCD}$ soft segments.

\section{Conclusions}

New colorless, transparent, high-molar-mass TPUs containing aliphatic polycarbonate soft segments and hard segments formed by a mixture of two chain extenders, diol OSOE and DMPA, with HDI or HMDI were synthesized by a onestep catalyzed melt polyaddition. On the basis of the experiment carried out, it may be concluded that the TPUs were characterized by very good tensile strength, with higher values being shown by the polymers based on HMDI (41.2-49.3 MPa vs. 37.8-44.9 MPa). They also revealed better transparency (transmittance at $800 \mathrm{~nm}$ : up to $92.7 \%$ vs. up to $75.4 \%$ ). On the other hand, the TPUs based on HDI exhibited lower $T_{\mathrm{g}} \mathrm{s}\left(-36\right.$ to $-29{ }^{\circ} \mathrm{C}$ vs. -20 to $\left.0{ }^{\circ} \mathrm{C}\right)$ and a higher degree of microphase separation. TPUs of both types showed a relatively good thermal stability. Their temperatures of $1 \%$ mass loss were contained within the range of 260-268 ${ }^{\circ} \mathrm{C}$.

Moreover, the obtained results indicate that these TPUs modified by DMPA generally showed improved transmittance, hardness, tensile and adhesive strengths, and worse elongation at break and somewhat poorer thermal stability compared to the corresponding non-modified ones. 
Open Access This article is distributed under the terms of the Creative Commons Attribution 4.0 International License (http://creativecommons.org/licenses/by/4.0/), which permits unrestricted use, distribution, and reproduction in any medium, provided you give appropriate credit to the original author(s) and the source, provide a link to the Creative Commons license, and indicate if changes were made.

\section{References}

1. Ulrich H (2003) Polyurethanes. In: Mark HF (ed) Encyclopedia of polymers science and technology, vol 4. Wiley, New Jersey, pp 26-72

2. Wirpsza Z (1993) Polyurethanes: chemistry, technology and applications. Ellis Horwood, New York

3. Resiak I, Rokicki G (2000) Modified polyurethanes for biomedical applications. Polimery-W 45:592-602

4. Zdrahala RJ (1996) Small caliber vascular grafts. 2. Polyurethanes revisited. J Biomater Appl 11:37-61

5. Hasirci N, Aksoy EA (2007) Synthesis and modifications of polyurethanes for biomedical purposes. High Perform Polym 19:621-637

6. Tang DL, Macosko CW, Hillmyer MA (2014) Thermoplastic polyurethane elastomers from biobased poly(delta-decalactone) diols. Polym Chem-UK 5:3231-3237

7. Dempsey DK, Robinson JL, Iyer AV, Parakka JP, Bezwada RS, Cosgriff-Hernandez EM (2014) Characterization of a resorbable poly(ester urethane) with biodegradable hard segments. J Biomat Sci-Polym E 25:535-554

8. Yeganeh H, Ghaffari M, Jangi A (2009) Diaminobisbenzothiazole chain extended polyurethanes as a novel class of thermoplastic polyurethane elastomers with improved thermal stability and electrical insulation properties. Polym Adv Technol 20:466-472

9. Padmavathy T, Srinivasan KSV (2003) Liquid crystalline polyurethanes-a review. J Macromol Sci Pol R C43:45-85

10. Kultys A, Puszka A (2014) Transparent poly(thiourethane-urethane)s based on dithiol chain extender. Synthesis and characterization. J Therm Anal Calorim 117:1427-1439

11. Puszka A, Kultys A (2017) The influence of soft segments on some properties of new transparent segmented polyurethanes. Polym Adv Technol 28:1937-1944

12. Kultys A, Podkoscielny W (1996) Polymers containing sulfur in the side chain. J Appl Polym Sci 61:1781-1788

13. Byczyński $€$ (2013) Effect of different polyethers on surface and thermal properties of poly(urethane-siloxane) copolymers modified with side-chain siloxane. J Therm Anal Calorim 114:397-408

14. Vitale A, Priola A, Tonelli C, Bongiovanni R (2014) Improvement of adhesion between a UV curable fluorinated resin and fluorinated elastomers: effect of chemical modification onto the mechanical properties of the joints. Int J Adhes Adhes 48:303-309

15. Rogulska M, Kultys A, Lubczak J (2015) New thermoplastic polyurethane elastomers based on aliphatic-aromatic chain extenders with different content of sulfur atoms. J Therm Anal Calorim 121:397-410

16. Rogulska M, Kultys A (2016) Aliphatic polycarbonate-based thermoplastic polyurethane elastomers containing diphenyl sulfide units. J Therm Anal Calorim 126:225-243

17. Rogulska M, Kultys A, Pikus S (2017) The effect of chain extender structure on the properties of new thermoplastic poly(carbonate-urethane)s derived from MDI. J Therm Anal Calorim 127:2323-2339

18. Rogulska M (2018) Transparent sulfur-containing thermoplastic polyurethanes with polyether and polycarbonate soft segments. Polym Bull 75:1211-1235

19. Klee D, Höcker H (2000) Polymers for biomedical applications: improvement of the interface compatibility. In: Eastmond GC, Höcker H, Klee D (eds) Biomedical applications polymer blends. Advances in polymer Science, Vol. 149, Springer, Berlin, Heidelberg, pp 1-58

20. Čulin J, Šmit I, Veksli Z et al (2006) Phase morphology of functionalized polyester polyurethanes. Effect of functional group concentration. Polym Int 55:285-291 
21. KosheelaDevi PP, Tuan Noor Maznee TI, Hoong SS et al (2016) Performance of palm oil-based dihydroxystearic acid as ionizable molecule in waterborne polyurethane dispersions. J Appl Polym Sci 133:43614

22. Žagar E, Žigon E (1999) Dilute solution behaviour of hexamethylene diisocyanate-based carboxylated polyurethanes and related ionomers in tetrahydrofuran. Polymer 40:2727-2735

23. Žagar E, Žigon E (2000) Solution properties of carboxylated polyurethanes and related ionomers in polar solvents (DMF and LiBr/DMF). Polymer 41:3513-3521

24. Antony P, De SK (2001) Ionic thermoplastic elastomers: a review. J Macromol Sci, Polym Rev 41:41-77

25. Harjunalanen T, Lahtinen M (2003) The effects of altered reaction conditions on the properties of anionic poly(urethane-urea) dispersions and films cast from the dispersions. Eur Polym J 39:817-824

26. Zhang S, Miao W, Zhou Y (2004) Reaction study of water-borne polyurethanes based on isophorone diisocyanate, dimethylol propionic acid, and poly(hexane neopentyl adipate glycol). J Appl Polym Sci 92:161-164

27. Matsunaga K, Nakagawa K, Sawai S et al (2005) Synthesis and characterization of polyurethane anionomers. J Appl Polym Sci 98:2144-2148

28. Barikani M, Valipour Ebrahimi M, Seyed Mohaghegh SM (2007) Preparation and characterization of aqueous polyurethane dispersions containing ionic centers. J Appl Polym Sci 104:3931-3937

29. Lu MG, Lee JY, Shim MJ, Kim SW (2002) Thermal degradation of film cast from aqueous polyurethane dispersions. J Appl Polym Sci 85:2552-2558

30. Manvi GN, Jagtap RN (2010) Effect of DMPA content of polyurethane dispersion on coating properties. J Dispersion Sci Technol 31:1376-1382

31. Penczek S, Frisch KC, Szczepaniak B, Rudnik E (1993) Synthesis and properties of liquid crystalline polyurethanes. J Polym Sci A: Polym Chem 31:1211-1220

32. Gorna K, Polowinski S, Gogolewski S (2002) Synthesis and characterization of biodegradable poly ( $\varepsilon$-caprolactone urethane)s. I. Effect of the polyol molecular weight, catalyst, and chain extender on the molecular and physical characteristics. J Polym Sci A: Polym Chem 40:156-170

33. Gunatillake PA, Meijs GF, Mccarthy SJ, Adhikari R, Sherriff N (1998) Synthesis and characterization of a series of poly(alkylene carbonate) macrodiols and the effect of their structure on the properties of polyurethanes. J Appl Polym Sci 69:1621-1633

34. Lee DK, Tsai HB, Tsai RS, Chen PH (2007) Preparation and properties of transparent thermoplastic segmented polyurethanes derived from different polyols. Polym Eng Sci 47:695-701

35. Puszka A (2018) Thermal and mechanical behavior of new transparent thermoplastic polyurethane elastomers derived from cycloaliphatic diisocyanate. Polymers 10(5):537

36. Puszka A, Kultys A, Rogulska M (2018) Influence of DMPA content on the properties of new thermoplastic poly(ether-urethane) elastomers. J Elastomers Plast 50:140-150

37. Rogulska M, Kultys A, Puszka A (2017) New thermoplastic poly(carbonate-urethane)s based on chain extenders with sulfur atoms. Chem Pap 71:1195-1204

38. Jha GS, Seshadri G, Mohan A et al (2008) Sulfur containing optical plastics and its ophthalmic lenses applications. E-Polymers 8:376-402 